\title{
Plajiyogranitler İçerisindeki Gabroyik Anklavların Petrografik Bileşimleri ve Mineral kimyası özellikleri; Mersin ofiyolitinde Dalma-Batma Zonu Magma Oluşumuna Dair Kanıtlar (Güney Türkiye)
}

\author{
Nusret Nurlu ${ }^{1}$, Nil Yapıcı ${ }^{2}$, Gökçe Şimşek ${ }^{1}$, Ahmet Can Akıncı ${ }^{1}$, Sedat Türkmen ${ }^{1}$ \\ ${ }^{1}$ Çukurova Üniversitesi, Mühendislik Fakültesi, Jeoloji Mühendisliği Bölümü, Adana. \\ ${ }^{2}$ Çukurova Üniversitesi, Mühendislik Fakültesi, Maden Mühendisliği Bölümü, Adana. \\ e-posta: nusretnurlu@gmail.com ORCID ID: https://orcid.org/0000-0002-3293-150X \\ Geliş Tarihi: 11.09.2018 ; Kabul Tarihi: 22.02.2019
}

Öz

Bu çalışmada Iç Toros Kenet Kuşağında gözlenen Mersin ofiyolitini kesen plajiyogranitler içerisinde bulunan Mafik Mikrogranuler Anklavlar (MME) ilk kez çalışılmış olup, (Pamukluk barajı ve çevresi) mineral kimyası analizleri sunulmuştur. Bölgeden elde edilen $\mathrm{MME}^{\prime}$ lerin detaylı petrografi incelemeleri

Anahtar kelimeler Mersin; Plajiogranit; MME; Mineral Kimyası; Ofiyolit sonucunda bunların gabroyik karakterde olmakla beraber bir kısım örneklerin diyoritik oldukları ortaya konulmuştur. Plajiyogranitik kayalar içerisinde boyutları $5 \mathrm{~cm}$ 'den $50 \mathrm{~cm}$ 'e kadar değişen Mafik Mikrogranular Anklavlar (MME) gözlenmektedir. Çalışılan MME'lerden elde edilen klinopiroksen analizlerinin $\mathrm{Mg}^{\#}$ numaraları 73.60 ile 86.28 arasında ve plajiyoklazların Anortit (An) içerikleri 88.5 ile 90.8 arasında değişmektedir. Kimyasal analizler sonucunda MME'lerden elde dilen plajiyoklazların çoğunlukla anortit-bitovnit karakterinde oldukları ve Wo-En-Fs üçlü diyagramında değerlendirilen veriler ışığında klinopiroksenlerin diyopsit oldukları ortaya konulmuştur. Çalışılan MME'lerin Mersin ofiyolitine ait mafik kümülatlara benzer özellikler sundukları ve ada yayı ortamında oluştukları belirlenmiştir.

\section{Mineral Chemistry and Petrographic Compositions of the Gabbroic Enclaves in the Plagiogranites; Evidence on Supra-Subduction Zone Type Magma Genesis in Mersin ophiolite (South Turkey)}

\begin{abstract}
As a result of the detailed petrographic studies of the Mafic microgranular enclaves (MMEs) obtained from the region, it was revealed that some of the samples were dioritic with gabbroic character. In this study, MMEs in the plagiogranites cutting Mersin ophiolite observed in the Inner Taurus Suture Zone

Keywords

Mersin; Plagiogranite; MME; Mineral Chemistry; Ophiolite were studied for the first time and the mineral chemistry analyses were presented. MMEs are varying in size from $5 \mathrm{~cm}$ to $50 \mathrm{~cm}$ were observed within the plagiogranitic rocks of Mersin ophiolite. The clinopyroxene analyses obtained from the studied MMEs presented $\mathrm{Mg}^{\#}$ numbers ranging from 73.60 to 86.28 and also anorthite (An) contents of plagioclases ranging from 88.5 to 90.8 . The chemical analysis revealed that the plagioclases obtained from MMEs are mostly anorthite-bitovnite and the clinopyroxenes are diopsides according to Wo-En-Fs triple diagram. It is determined that the studied MMEs presented similar properties to the mafic cumulates of the Mersin ophiolite and formed in the island arc environment.
\end{abstract}




\section{Giriş}

Anadolunun güneyinde izlenen ofiyolitlerin de içerisinde bulunduğu Doğu Akdeniz ofiyolitleri iki kuşak altında değerlendirilmektedir. Bu kuşaklardan ilki Peri- Arap kuşağında; Baer Bassit, Hatay, Troodos, Guleman, Cilo, Zagros ve Oman (Ricou, 1971) ve ikincisi Toros kuşağında; Ali hoca, Likya napı, Pozantı-Karsantı, Beyşehir-Hoyran napı,

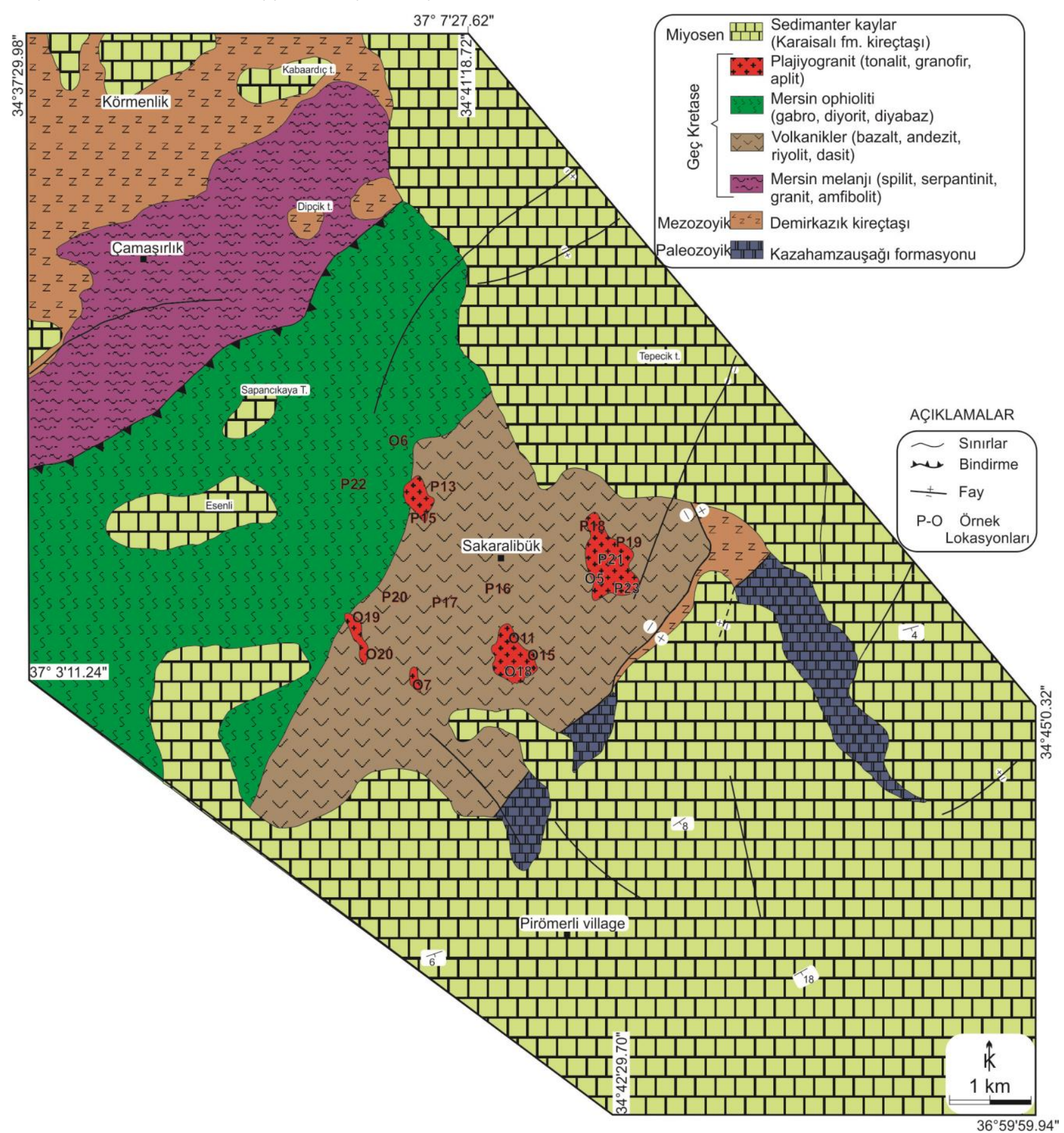

Mersin ofiyolitleridir. Genellikle birimler metamorfik dilimler ve ofiyolitik melanjlarla birlikte izlenmektedir (Juteau, 1980; Dilek ve Moores, 1990). Bölgede çalışma yapmış pek çok araştırmacı

Şekil 1. Çalışma alanı detaylı jeoloji haritası (Türkmen 1994'ten modifiye edilmiştir). 
Anadolu'da ofiyolitlerin Dalma-batma (SSZ) zonunda oluştuklarını ortaya koymuşlardır (Yılmaz vd., 1993; Robertson, 1994; Parlak vd., 1995). Mersin Ofiyoliti Doğu Akdeniz bölgesinde, Toros karbonat ekseninin güneyinde yer alan Geç Kretase yaşlı eksikli bir ofiyolit istifi sunmaktadır (Şengör ve Yılmaz, 1981; Dilek ve Moores, 1990)(Şekil 1, 3b). Parlak ve Delaloye 1996 'da yaptıkları çalışmada çalışma alanında ofiyolitik melanj, Sub-ofiyolitik metamorfikler, manto tektonitleri (verlit, dünit ve harzburjit), ultramafik (serpantinize dunit, verlit, piroksenit) ve mafik (anortozit, gabro, olivinli gabro, ve lökogabro) kumulatlar, izotropik gabrolar, plajiyogranitler, alkali-toleyitik bazaltik volkaniklerin gözlendiğini ve Mersin ofiyolitinin dalma-batma zonu ortamında oluştuklarını ortaya koymuşlardır. Nurlu vd., 2018a, b çalışma alanında gözlenen plajiyogranitler üzerinde yaptıkları araştırmada plajiyogranitlerin Mersin ofiyolitine ait gabro ve volkanojenik kayaları kesmekte olduklarını ve bu kayaların I-tipi, kalk-alkali volkanik yay graniti karakterinde olduklarını ve zirkonlardan elde edilen $\mathrm{U} / \mathrm{Pb}$ kristallenme yaşlarının $93.0 \pm 1.5$ ile $94.2 \pm 2.4$ my olduğunu ortaya koymuşlardır.

Lacroix (1890) ilk kez Mafik mikrogranüler Anklav (MME) terimini kullanmıştır ve felsik magmatik kayaların içerdiği koyu renkli, bazik kayaç parçalarını tanımlamıştır.

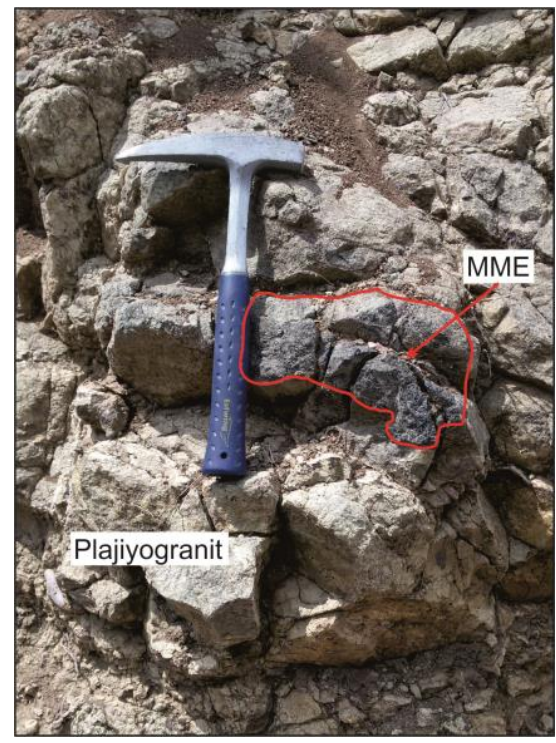

Şekil 2. Mafik mikrogranuler anklavların (MME) arazi görünümü.

Farklı araştırmacılar anklavların adlandırılmasına yönelik değişik tanımlamalar önermişlerdir ancak literatürde bulunan en güncel tanımlama Didier ve Barbarin (1991) tarafından ortaya konulmuştur (Çizelge 1).

Illksel bazik magmanın kalıntılarını temsil eden mafik mikrogranüler anklavlar (MME) üzerine yapılan detaylı petrografik ve jeokimyasal çalışmalar granitik magmanın üretimi ve kaynak kayacın oluşumu ile ilişkili önemli ipuçlarını ortaya koymaktadırlar (White ve Chapel, 1977: Akal ve Helvacı, 1999). Mafik Mikrogranüler Anklavlar (MME) granitik ve plajiogranitik kayalar içerisinde bol miktarda bulunmakta olup, şekil olarak küreselden elipsoidala kadar ve boyutları birkaç santimetre ila 30-40 santimetre arasında değişen, heterojen bir görünüşe sahiptirler. Tüm MME'lerin ince taneli mikrogranüler dokusu vardır. Anklavlar ve ana kayaçlar arasındaki temaslar çoğunlukla yuvarlak ve düzensizdir. Bazı mafik kuşaklar, dış kısımlarında açık renkli bir geçiş zonuna sahiptirler (Şekil 2). Anklavların ana kayaçların fenokristallerini içerdikleri dikkat çekmekte olup (Şekil 2) plajiyogranitik intrüzyonlarda MME'ler yaygın olarak gözlenmektedir. Bu, iki felsik ve mafik magmanın birbirine karışımını gerektirmektedir. Buna ek olarak, ince taneli felsik dayklarda zenginleştirilmiş düzensiz kenarlı ve elipsoyidal anklavlar plajiyogranitlerde mevcut (Şekil 2) olup mafik anklavların ayrışmasının, magmanın ana magma ile karışması sonucunda meydana geldiğine işaret etmektedir (Didier ve Barbarin).

Çizelge 1. Güncel anklav tanımı (Didier ve Barbarin, 1991).

\begin{tabular}{|c|c|c|c|c|c|}
\hline \multirow[b]{2}{*}{ A } & Terim & Bulunuş Şekli & Sınır İlişkisi & Biçim & $\begin{array}{c}\text { Karakteristik } \\
\text { Özellik }\end{array}$ \\
\hline & Ksenolit & $\begin{array}{l}\text { Yan Kayaç } \\
\text { Parçaları (Hornfels) }\end{array}$ & Keskin & Köşeli & $\begin{array}{l}\text { Kontak } \\
\text { Metamorfizma } \\
\text { dokusu ve Mineralleri }\end{array}$ \\
\hline $\mathrm{N}$ & $\begin{array}{l}\text { Kseno- } \\
\text { Kristal }\end{array}$ & $\begin{array}{l}\text { Izole Edilmiş } \\
\text { Yabancı Kristaller }\end{array}$ & Keskin & Küresel & $\begin{array}{l}\text { Korozton } \\
\text { Reaksiyon Kuşağı }\end{array}$ \\
\hline $\mathrm{K}$ & $\begin{array}{l}\text { Mikamsı } \\
\text { Anklav }\end{array}$ & $\begin{array}{l}\text { Erime Kalıntısı } \\
\text { (Restit) }\end{array}$ & $\begin{array}{l}\text { Keskin (Ozellikle } \\
\text { biyotit kabuk } \\
\text { ile keskinleşmiş) }\end{array}$ & Merceksi & $\begin{array}{l}\text { Metamorfik Doku, } \\
\text { Mikalar ve Al' ce } \\
\text { Zengin Mineraller }\end{array}$ \\
\hline \multirow[t]{2}{*}{$\mathrm{L}$} & Şiliriyen & $\begin{array}{l}\text { Düzensizleștirilmiş } \\
\text { Anklav }\end{array}$ & Dereceli & Elipsoyidal & $\begin{array}{l}\text { Düzlemsel } \\
\text { Yapilar }\end{array}$ \\
\hline & \begin{tabular}{l|} 
Felsik \\
Mikrogranüler \\
Anklav (FME)
\end{tabular} & $\begin{array}{l}\text { Düzensizleștirilmis } \\
\text { Ince Taneli Kenar }\end{array}$ & $\begin{array}{l}\text { Keskin veya } \\
\text { Dereceli }\end{array}$ & $\begin{array}{l}\text { Yuvarlağımsı } \\
\text { Elipsoyidal }\end{array}$ & $\begin{array}{l}\text { Ince Taneli } \\
\text { Magmatik Doku }\end{array}$ \\
\hline \multirow[t]{2}{*}{ V } & $\begin{array}{l}\text { Mafik } \\
\text { Mikrogranüler } \\
\text { Anklav (MME) }\end{array}$ & $\begin{array}{l}\text { Eşyaşııı Mafik } \\
\text { Magma Damlacı̆̆ı }\end{array}$ & $\begin{array}{l}\text { Çoğunlukla } \\
\text { Keskin }\end{array}$ & $\begin{array}{l}\text { Yuvarlağımsı } \\
\text { Elipsoyidal }\end{array}$ & $\begin{array}{l}\text { Ince Taneli } \\
\text { Magmatik Doku }\end{array}$ \\
\hline & $\begin{array}{l}\text { Kümülat } \\
\text { Anklav } \\
\text { Otolit }\end{array}$ & $\begin{array}{l}\text { Düzensizleștirilmiş } \\
\text { Kümülat }\end{array}$ & $\begin{array}{l}\text { Çoğunlukla } \\
\text { Dereceli }\end{array}$ & $\begin{array}{l}\text { Yuvarlağımsı } \\
\text { Elipsoyidal }\end{array}$ & $\begin{array}{l}\text { Ince Taneli } \\
\text { Kümülat Doku }\end{array}$ \\
\hline
\end{tabular}

\section{Materyal ve Metot}

\subsection{Petrografi}

Yaklaşık 30 adet kayaç örneği Çukurova Üniversitesi Jeoloji Mühendisliği Bölümünde ince kesit çalışmaları için hazırlanmıştır. Petrografi çalışmaları 
sonucunda mineral kimyası analizleri için uygun örnekler seçilmiştir.

\subsection{Mineral Kimyası Analizleri}

Dört numune için ince kesitler (yaklaşık 30 mikron kalınlıkta olmak üzere) Alberta Üniversitesi'nde (Kanada) Yer ve Atmosfer Bilimlerinde (EAS) bulunan ince kesit laboratuvarı tarafindan hazırlanmıştır. Minerallerin ana element bileşimleri ve faz ilişkileri, Alberta Üniversitesi'ndeki Yer ve Atmosfer Bilimlerinde (EAS) elektron mikroprob tarafından analiz edilmiştir. Çalışma koşulları; 40 derece kalkış açısı, 20 kV'luk hızlanma gerilimi, 20 nA'lık huzme ve <1 mikron (tamamen odaklanmış). 13 elementin $\mathrm{K} \alpha \mathrm{X}$-ışını çizgileri, aşağıdaki kırınım kristalleri kullanılarak ölçüldü: PET (pentaeritritol) P, K, Ca, Ti, V, Cr; TAP (talyum hidrojen fitalat) - Na, $\mathrm{Mg}, \mathrm{Al}, \mathrm{Si}$; LiF (lityum florür) - Mn, Fe, Ni. 60 saniye kullanılan Na dışındaki tüm elemanlar için emisyon pikleri ve arka plan konumları için toplam 30 saniyelik sayım süreleri kullanılmıştır. Enterferans düzeltmeleri Ti'ye karşı enterferans için V'ye ve V'nin müdahalesi için $\mathrm{Cr}^{\prime}$ a ve $\mathrm{Cr}$ 'in müdahalesi için Mn'ye uygulanmıştır (Donovan vd., 1993). Armstrong (1988) ve mineral standartlarının seçimi analiz edilen mineral ile değişmiştir. Oksijen stokiyometri ile hesaplanmış ve veri azaltımına dahil edilmiştir. Temsili veriler, Çizelge (2) ve (3)'te gösterilmiştir.

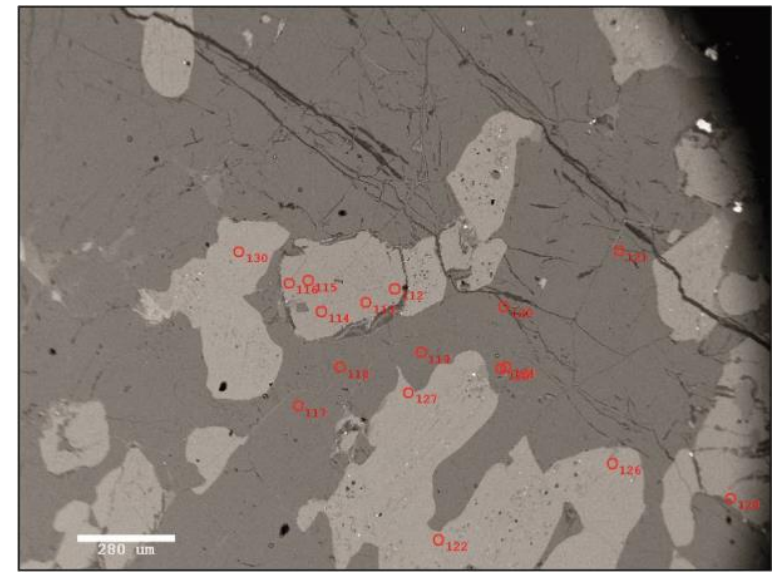

Şekil 3. Gabroyik anklavların SEM (scanning electron microscope) görüntüsü ve analiz edilen noktaların lokasyonları

\subsection{SEM (Scanning Electron Mmicroscope) Analizleri}

Taramalı elektron mikroskobu (SEM) tamamen dijital olup bilgisayar kontrolü ile çalışmaktadır ve ilgili analizler Alberta Üniversitesi'nde (Kanada) Yer ve Atmosfer Bilimlerinde (EAS) yapılmıştır. Taramalı elektron mikroskobu (SEM) 2- 5x-300.000x arası büyütme kapasitesine sahiptir. Tabaka film çekme ünitesi ve video-copy baskı ünitesi vardır. Elektron kaynağı tungsten filamenttir. Secondary ve Backscattered elektron dedektörüne sahiptir. Yüzey mikro yapıyı görüntüleyerek tanecik boyutu ve farklı kristollagrafik fazları dedekte etme kabiliyetine sahiptir. 5 eksen motorize kartezyen kontrolü $\left(X=100 \mathrm{~mm}, \quad Y=120 \mathrm{~mm}, \quad Z=60 \mathrm{~mm}, \quad\right.$ Tilt $=0-90^{\circ}$, Dönme $=360^{\circ}$ ) ile çalışmaktadır. Geniş numune çemberine $(270 \mathrm{~mm} \times 270 \mathrm{~mm} \times 250 \mathrm{~mm})$ sahiptir. EDX ve WDX 600i X-Ray analiz spektrometrelerine sahiptir. EDX analizi Be-U arasındaki elementler için nitel (kalitatif) elemanter analiz özelliğine sahiptir.WDX $600 \mathrm{i}$ analizi 45 çeşit standart, 5 difraksiyon kristalli nicel (kantitatif) elemanter analiz özelliğine sahiptir. Örnek yüzeylerindeki "grain boundry"lerin özellikleri belirlenebilmektedir

\section{Bulgular}

\subsection{Petrografi}

Çalışma alanından belirlenen mafik mikrogranüler anklavlar plajiyogranitik kayalar içerisinde değişik boyut ve biçimlerdedir (Şekil 2). Hemen tamamının biçimleri küresel, dairesel ve elipsoyidal olup ana kayaç ile keskin sınırlıdır. Belirgin bir gruplaşma göstermeyen mafik mikrogranüler anklavların çoğunlukla gabroyik ve diyoritik bileşime sahip oldukları yapılan petrografik çalışmalar sonucunda ortaya konulmuştur. Çalışma alanından derlenen mafik mikrogranüler anklavlardan (MME) seçilmiş örnekler üzerinde yapılan petrografik tanımlama çalışmalarının sonucunda elde edilen veriler aşağıda sunulmuştur.

\subsubsection{Diyoritik MME}

Kayaçta hakim minerali plajiyoklaslar (andezin) temsil etmektedir ve yaklaşık olarak \%55-57 oranında gözlenmektedirler. Plajiyoklas kristallerinin büyük bölümü ileri derecede alterasyona maruz kalmış olup çoğunlukla kalsitleşme ve kaolenleşme gözlenmektedir. Incelenen kayaçta hakim mafik minerali amfiboller temsil etmekte ve hornblend (yeşil) türü oldukları gözlenmektedir. Kayaç içerisinde yaklaşık \% 28-30 
oranında gözlenen amfibollerin bir kısmında kloritleşme ve opasitleşme izlenmektedir (Şekil 4.). Kuvars kayaç içerisinde yaklaşık \%2-3 oranında bulunmaktadır.

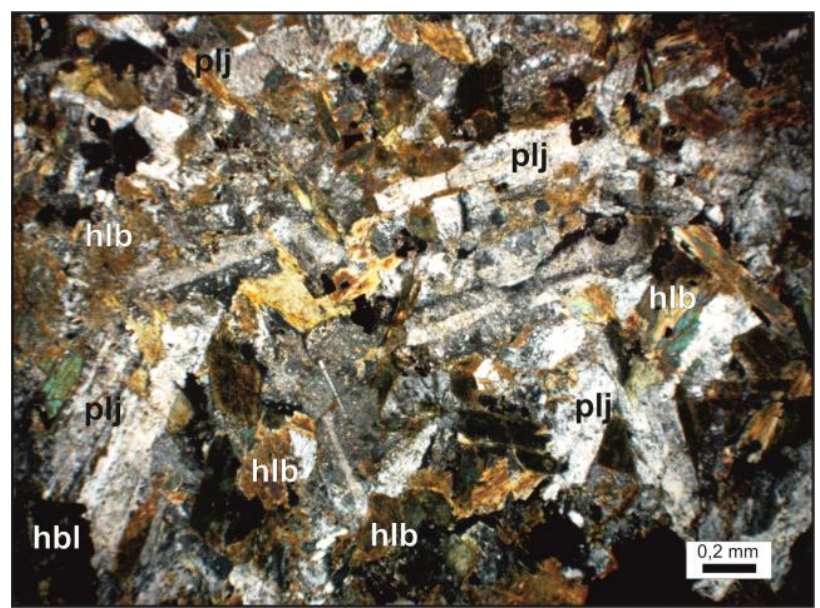

Şekil 4. Diyoritik MME'lere ait ince kesit görünümü (Çift nikol; plj: plajiyoklas, hbl: hornblend)

\subsubsection{Gabroyik MME}

Çalışma alanından derlenen MME'lerin büyük bölümü gabroyik kayalardan oluşmaktadır. Bu kayaçlar içerisindeki hakim mineral plajiyoklas (bitovnit-anortit) olarak belirlenmiştir ve yaklaşık olarak \%57-60 oranındadırlar. Plajiyoklasların büyük çoğunluğu lata (levha) şekilli ve belirgin polisentetik ikizlenmeleri ile karakteristiktirler ve bir kısmında hidrarjilitleşme, türü alterasyonlar gözlenmektedir (Şekil 5).

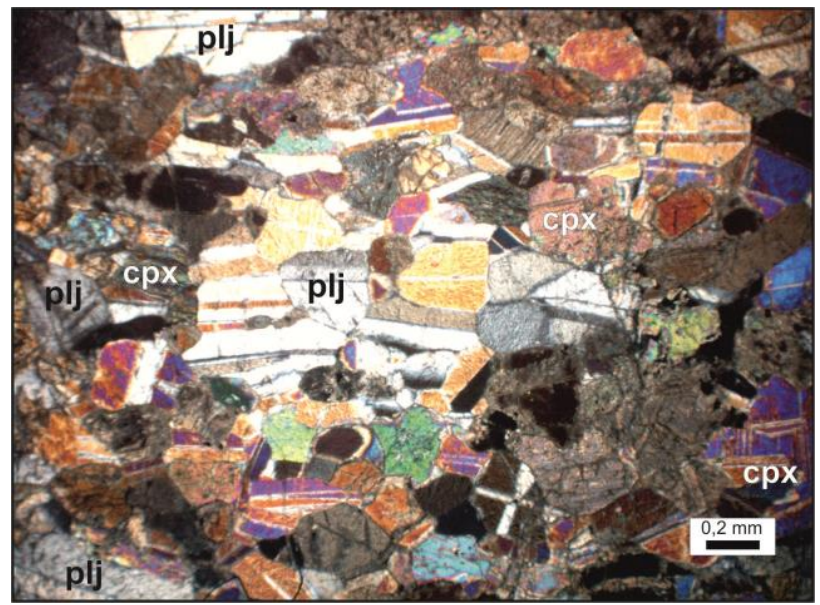

Şekil 5. Gabroyik MME'lere ait ince kesit görünümü (Çift nikol; plj: plajiyoklas, cpx: klinopiroksen)

Incelenen kayaçta, hemen tamamı sarı ve kahverengi girişim renklerine sahip, bir kısmında çift yönde, birbirine dik olarak gelişmiş dilinim izleri gözlenen klinopiroksen minerallerine rastlanmıştır ve kayaçta yaklaşık olarak \%25-30 oranında gözlenmiştir. Kayaçta \%3-5 oranında bulunan amfibol minerallerinin hornblend (yeşil) oldukları ve küçük bir kısmının sekonder uralitleşme yoluyla piroksenlerden itibaren oluştukları gözlenmiştir (Şekil 5).

\subsection{Mineral Kimyası}

Mersin ofiyolitinde plajiogranitlerin içerisinde gözlenen MME'lerden elde edilen kayaçlardan klinopiroksen ve feldispat (plajiyoklas) mineralleri üzerinde toplam 30 adet noktanın analizi yapılmıştır (Çizelge 2, 3, 4).

\subsubsection{Feldispat}

İnceleme alanında bulunan anklavlarda gözlenen plajiyoklas türü feldispatların mineral kimyası analizleri Çizelge (2)'de verilmiştir. Bu kayaçlarda analiz edilen plajiyoklasların $\mathrm{SiO}_{2}$ içeriği 44,74-45,50; $\mathrm{Al}_{2} \mathrm{O}_{3}$ içeriği 35,01-05,40; $\mathrm{Fe}_{2} \mathrm{O}_{3}$ içeriği 0,43-0,53; $\mathrm{CaO}$ içeriği 18,35-18,76; MgO içeriği 0-0,08 arasında değişmektedir (Çizelge 2). Mersin ofiyolitini kesen plajiyogranitler içerisindeki MME'lere ait plajiyoklaslar oldukça dar bir alanda bileşim sunmakta olup anortit (An) içeriği \%88,5 ile 90,8 arasında değişmektedirler ve bitovnit, anortit bileşiminde oldukları belirlenmiştir (Şekil 6).

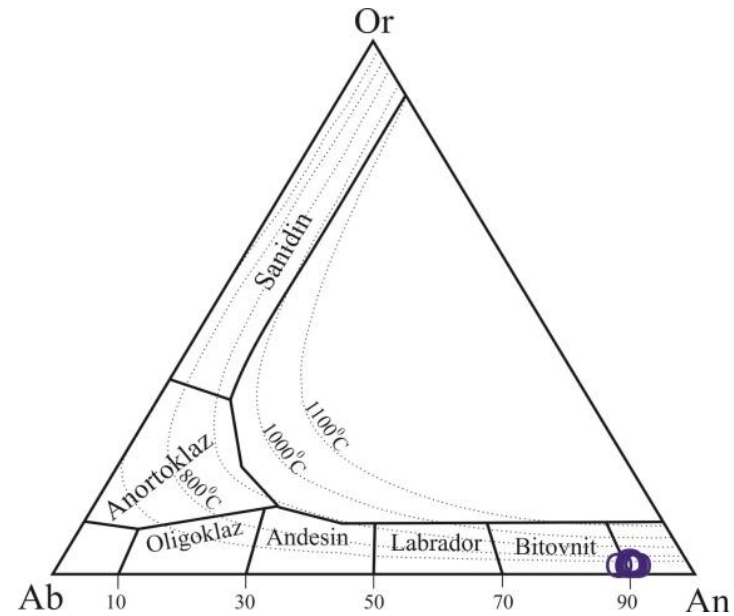

Şekil 6. Mafik mikrogranülar anklavlardan analiz edilen plajiyoklas minerallerinin türleri (Leake vd., 1997).

Plajiyoklaslarda gözlenen bu dar spektrumlu bileşim aralı̆̆ı evrimleşmiş kayaçlardan kaynaklanmaktadır. Incelenen kayaçlardaki anortit bakımından zengin plajiyoklasların varlığı magma farklılaşması sırasında magmadaki su buharı basıncının yüksek olduğunu göstermektedir (Green ve Ringwood, 1968; Nesbitt ve Hamilton, 1970; Arculus ve Wills, 1980; Sisson ve 
Grove, 1993, Pandjasawatwong ve ark., 1997: Bağcı, 2004). Mafik mikrogranular anklavlardan analiz edilen plajiyoklaslar hem ters hem de normal zonlanma göstermektedir ve bu durumda kümülat kayaçların kristallenmesi esnasında interkümülüs fazda suyun bulunmasının ters zonlanmayı oluşturabileceği düşünülmektedir (Arculus ve Wills, 1980).
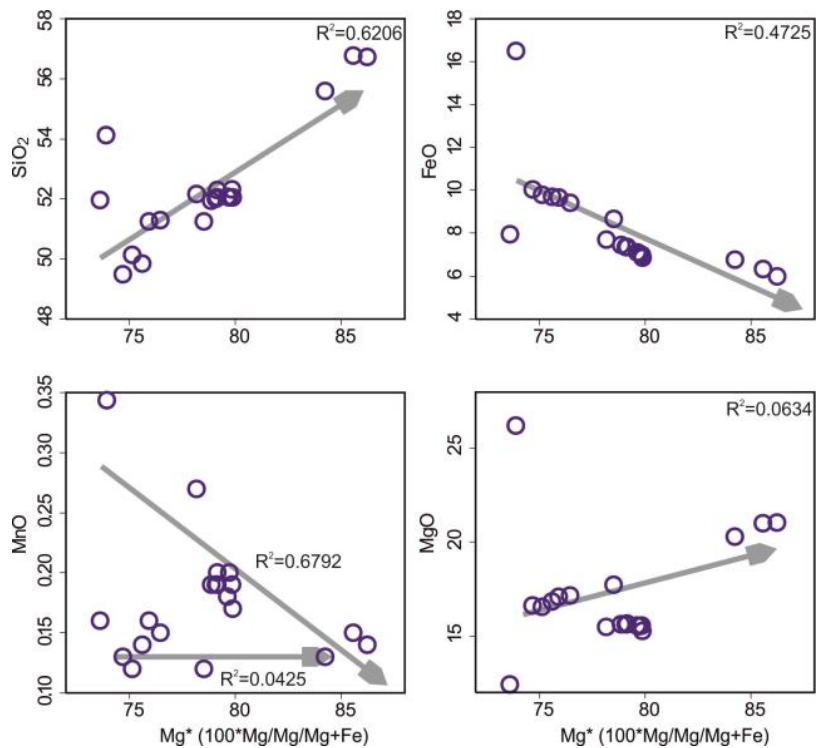

Şekil 7. Mersin ofiyolitine ait plajiogranitler içerisinde gözlenen MME'ler içerisinde analiz edilen klinopiroksenlerin magnezyum numaraları $\left(\mathrm{Mg}^{\#}\right)$ ile seçilen bazı ana element ve oksit içeriklerinin varyasyon diyagramı.

3.2.2. Klinopiroksen Çalışma alanından derlenen MME'lere ait klinopiroksenlerin magnezyum numaraları $\left(\mathrm{Mg}^{\#}=100 * \mathrm{Mg} / \mathrm{Mg}+\mathrm{Fe}\right)$ ile seçilmiş bazı ana element ve oksitlerin varyasyon (Harker tipi) diyagramı incelendiğinde $\mathrm{MnO}$ ve $\mathrm{FeO}$ değerlerinin artan $\mathrm{Mg}^{\#}$ içeriklerine göre azalarak negatif korelasyon gösterdikleri ve $\mathrm{MgO}$ ile $\mathrm{SiO} 2$ değerlerinin ise $\mathrm{Mg}^{\#}$ içeriğine kıyasla artarak pozitif trend sundukları gözlenmektedir (Çizelge 3, 4; Şekil 7).

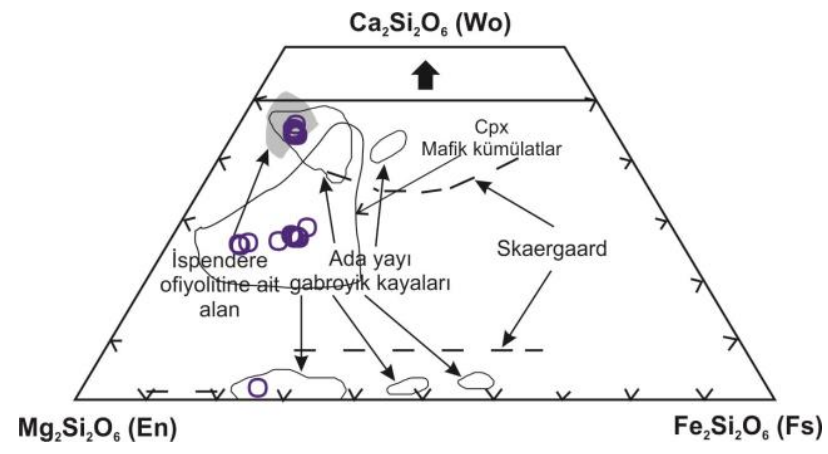

Şekil 8. MME'lere ait kayalarda gözlenen klinopiroksenlerin $\quad F s-E n-W o$ üçgen diyagramındaki konumları (Burns, 1985).

Mersin ofiyolitini kesen plajiyogranitlere ait MME'ler içerisinde gözlenen klinopiroksenlerin (diyopsit) Wo-En-Fs üçlü sınıflama diyagramında konumları incelendiğinde (Burns, klinopiroksenlerin adayayı gabroyik kayaçlarında ve İspendere ofiyolitinde gözlenen gabroyik kayaçlara benzerlikler sundukları gözlenmiştir (Şekil 8).

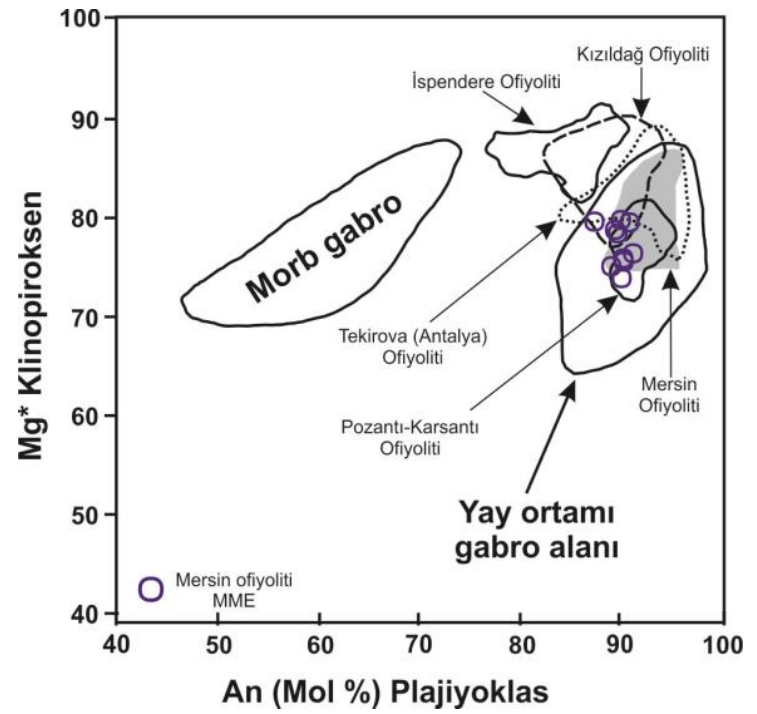

Şekil 9. Mersin ofiyolitini kesen plajiyogranitler içerisinde MME'lerden analiz edilen plajiyoklasın anortit (An) içeriğinin klinopiroksenlerdeki $\mathrm{Mg}^{\#}$ numarasına karşılık değişim diyagramı. 
Çizelge 2. Plajiyogranitler içerisindeki gabroyik anklavlara ait plajiyoklasların (bitovnit-anortit) mineral kimyası

\begin{tabular}{|c|c|c|c|c|c|c|c|c|c|c|}
\hline Örnek No: & 012-1 & O12-2 & 012-3 & 012-4 & 012-5 & 012-6 & 012-7 & $012-8$ & 012-9 & $012-10$ \\
\hline $\mathrm{SiO}_{2}$ & 45.14 & 45.00 & 44.74 & 44.90 & 44.89 & 44.92 & 45.07 & 44.97 & 44.95 & 45.50 \\
\hline $\mathrm{TiO}_{2}$ & 0.00 & 0.00 & 0.00 & 0.00 & 0.00 & 0.00 & 0.00 & 0.00 & 0.00 & 0.00 \\
\hline $\mathrm{Al}_{2} \mathrm{O}_{3}$ & 35.14 & 35.21 & 35.29 & 35.31 & 35.23 & 35.40 & 35.15 & 35.20 & 35.33 & 35.01 \\
\hline $\mathrm{FeO}$ & 0.49 & 0.43 & 0.53 & 0.49 & 0.45 & 0.52 & 0.52 & 0.52 & 0.48 & 0.50 \\
\hline $\mathrm{NiO}$ & 0.00 & 0.00 & 0.00 & 0.00 & 0.00 & 0.00 & 0.00 & 0.00 & 0.02 & 0.00 \\
\hline MgO & 0.04 & 0.03 & 0.03 & 0.00 & 0.02 & 0.05 & 0.04 & 0.08 & 0.04 & 0.07 \\
\hline $\mathrm{CaO}$ & 18.56 & 18.64 & 18.76 & 18.69 & 18.74 & 18.76 & 18.69 & 18.69 & 18.72 & 18.35 \\
\hline $\mathrm{Na}_{2} \mathrm{O}$ & 1.20 & 1.15 & 1.04 & 1.11 & 1.11 & 1.06 & 1.18 & 1.13 & 1.13 & 1.31 \\
\hline $\mathbf{K}_{2} \mathbf{O}$ & 0.00 & 0.01 & 0.01 & 0.01 & 0.01 & 0.02 & 0.00 & 0.00 & 0.01 & 0.01 \\
\hline $\mathbf{P}_{2} \mathrm{O}_{5}$ & 0.00 & 0.00 & 0.03 & 0.00 & 0.00 & 0.02 & 0.03 & 0.03 & 0.00 & 0.03 \\
\hline TOTAL & 100.57 & 100.47 & 100.43 & 100.51 & 100.45 & 100.75 & 100.68 & 100.62 & 100.68 & 100.78 \\
\hline $\mathbf{S i}$ & 2.07 & 2.06 & 2.05 & 2.06 & 2.06 & 2.05 & 2.06 & 2.06 & 2.06 & 2.08 \\
\hline $\mathrm{Al}^{\mathrm{IV}}$ & 0.93 & 0.94 & 0.95 & 0.94 & 0.94 & 0.95 & 0.94 & 0.94 & 0.94 & 0.92 \\
\hline $\mathrm{Al}^{\mathrm{VI}}$ & 0.96 & 0.96 & 0.96 & 0.96 & 0.96 & 0.96 & 0.96 & 0.96 & 0.96 & 0.96 \\
\hline $\mathrm{Fe}^{2+}$ & 0.02 & 0.02 & 0.02 & 0.02 & 0.02 & 0.02 & 0.02 & 0.02 & 0.02 & 0.02 \\
\hline $\mathbf{C a}$ & 0.91 & 0.92 & 0.92 & 0.92 & 0.92 & 0.92 & 0.92 & 0.92 & 0.92 & 0.90 \\
\hline $\mathbf{N a}$ & 0.11 & 0.10 & 0.09 & 0.10 & 0.10 & 0.09 & 0.10 & 0.10 & 0.10 & 0.12 \\
\hline Total & 5.00 & 5.00 & 5.00 & 5.00 & 5.00 & 5.00 & 5.00 & 5.00 & 5.00 & 5.00 \\
\hline Or & 0.0 & 0.1 & 0.1 & 0.1 & 0.1 & 0.1 & 0.0 & 0.0 & 0.1 & 0.1 \\
\hline $\mathbf{A b}$ & 10.5 & 10.0 & 9.1 & 9.7 & 9.7 & 9.3 & 10.3 & 9.9 & 9.8 & 11.4 \\
\hline An & 89.5 & 89.9 & 90.8 & 90.2 & 90.3 & 90.6 & 89.7 & 90.1 & 90.1 & 88.5 \\
\hline
\end{tabular}

Çizelge 3. Plajiyogranitler içerisindeki gabroyik anklavlara ait klinopiroksenlerin mineral kimyası

\begin{tabular}{|c|c|c|c|c|c|c|c|c|c|c|}
\hline Örnek No: & O12C-1 & O12C-2 & O12C-3 & O12C-4 & O12C-5 & O12C-6 & O12C-7 & O12C-8 & O12C-9 & O12C-10 \\
\hline $\mathrm{SiO}_{2}$ & 50.13 & 51.25 & 51.29 & 51.25 & 49.85 & 52.07 & 51.94 & 54.12 & 52.04 & 52.05 \\
\hline $\mathrm{TiO}_{2}$ & 0.72 & 0.60 & 0.48 & 0.38 & 0.97 & 0.35 & 0.32 & 0.18 & 0.36 & 0.34 \\
\hline $\mathbf{A l}_{2} \mathbf{O}_{3}$ & 6.70 & 5.92 & 5.19 & 5.36 & 6.25 & 1.58 & 1.86 & 1.05 & 1.68 & 1.59 \\
\hline $\mathrm{Cr}_{2} \mathrm{O}_{3}$ & 0.05 & 0.06 & 0.00 & 0.06 & 0.15 & 0.05 & 0.04 & 0.03 & 0.05 & 0.06 \\
\hline $\mathrm{FeO}$ & 9.78 & 8.66 & 9.42 & 9.67 & 9.69 & 7.10 & 7.46 & 16.51 & 6.86 & 7.05 \\
\hline MnO & 0.12 & 0.12 & 0.15 & 0.16 & 0.14 & 0.18 & 0.19 & 0.35 & 0.17 & 0.20 \\
\hline MgO & 16.56 & 17.74 & 17.15 & 17.10 & 16.85 & 15.56 & 15.61 & 26.22 & 15.27 & 15.53 \\
\hline $\mathrm{CaO}$ & 12.24 & 12.04 & 12.62 & 12.43 & 12.15 & 22.51 & 22.08 & 1.22 & 22.87 & 22.59 \\
\hline $\mathrm{Na}_{2} \mathrm{O}$ & 0.92 & 0.85 & 0.44 & 0.48 & 0.78 & 0.20 & 0.18 & 0.00 & 0.21 & 0.18 \\
\hline $\mathbf{K}_{2} \mathbf{O}$ & 0.06 & 0.02 & 0.02 & 0.04 & 0.05 & 0.00 & 0.00 & 0.00 & 0.00 & 0.00 \\
\hline TOTAL & 97.44 & 97.41 & 96.90 & 97.01 & 97.09 & 99.69 & 99.79 & 99.77 & 99.63 & 99.68 \\
\hline $\mathbf{S i}$ & 1.882 & 1.914 & 1.940 & 1.936 & 1.881 & 1.928 & 1.922 & 1.968 & 1.929 & 1.928 \\
\hline $\mathbf{T i}$ & 0.020 & 0.017 & 0.014 & 0.011 & 0.028 & 0.010 & 0.009 & 0.005 & 0.010 & 0.009 \\
\hline Al & 0.296 & 0.261 & 0.231 & 0.239 & 0.278 & 0.069 & 0.081 & 0.045 & 0.073 & 0.069 \\
\hline $\mathrm{Fe}^{+3}$ & 0.000 & 0.000 & 0.000 & 0.000 & 0.000 & 0.068 & 0.068 & 0.009 & 0.061 & 0.067 \\
\hline $\mathrm{Cr}^{+3}$ & 0.001 & 0.002 & 0.000 & 0.002 & 0.004 & 0.001 & 0.001 & 0.001 & 0.001 & 0.002 \\
\hline $\mathrm{Fe}^{+2}$ & 0.307 & 0.271 & 0.298 & 0.305 & 0.306 & 0.151 & 0.163 & 0.493 & 0.151 & 0.151 \\
\hline Mn & 0.004 & 0.004 & 0.005 & 0.005 & 0.004 & 0.006 & 0.006 & 0.011 & 0.005 & 0.006 \\
\hline Mg & 0.927 & 0.988 & 0.967 & 0.963 & 0.948 & 0.859 & 0.861 & 1.421 & 0.844 & 0.857 \\
\hline Ca & 0.492 & 0.482 & 0.512 & 0.503 & 0.491 & 0.893 & 0.876 & 0.048 & 0.909 & 0.896 \\
\hline $\mathbf{N a}$ & 0.067 & 0.062 & 0.032 & 0.035 & 0.057 & 0.014 & 0.013 & 0.000 & 0.015 & 0.013 \\
\hline $\mathbf{K}$ & 0.003 & 0.001 & 0.001 & 0.002 & 0.002 & 0.000 & 0.000 & 0.000 & 0.000 & 0.000 \\
\hline Total & 4.000 & 4.000 & 4.000 & 4.000 & 4.000 & 4.000 & 4.000 & 4.000 & 4.000 & 4.000 \\
\hline Wo & 28.52 & 27.69 & 28.79 & 28.40 & 28.15 & 46.92 & 46.10 & 2.42 & 47.72 & 47.05 \\
\hline En & 53.69 & 56.76 & 54.44 & 54.36 & 54.32 & 45.12 & 45.34 & 72.44 & 44.33 & 45.01 \\
\hline Fs & 17.79 & 15.55 & 16.77 & 17.24 & 17.53 & 7.96 & 8.56 & 25.14 & 7.95 & 7.94 \\
\hline $\mathbf{M g}^{\#}$ & 75.11 & 78.50 & 76.44 & 75.92 & 75.61 & 79.62 & 78.86 & 73.90 & 79.87 & 79.70 \\
\hline
\end{tabular}


Çizelge 4. Plajiyogranitler içerisindeki gabroyik anklavlara ait klinopiroksenlerin mineral kimyası

\begin{tabular}{|c|c|c|c|c|c|c|c|c|c|c|}
\hline Örnek No: & O12C-11 & O12C-12 & O12C-13 & O12C-14 & O12C-15 & O12C-16 & O12C-17 & O12C-18 & O12C-19 & O12C-20 \\
\hline $\mathrm{SiO}_{2}$ & 52.06 & 52.32 & 52.01 & 52.30 & 52.16 & 56.78 & 56.74 & 55.60 & 51.95 & 49.49 \\
\hline $\mathrm{TiO}_{2}$ & 0.29 & 0.32 & 0.33 & 0.35 & 0.35 & 0.17 & 0.11 & 0.29 & 0.23 & 1.11 \\
\hline $\mathbf{A l}_{2} \mathbf{O}_{3}$ & 1.71 & 1.59 & 1.63 & 1.59 & 1.68 & 1.10 & 1.14 & 2.02 & 16.34 & 6.87 \\
\hline $\mathrm{Cr}_{2} \mathrm{O}_{3}$ & 0.04 & 0.05 & 0.04 & 0.05 & 0.06 & 0.00 & 0.00 & 0.05 & 0.00 & 0.17 \\
\hline $\mathrm{FeO}$ & 7.35 & 7.00 & 7.37 & 7.36 & 7.71 & 6.32 & 5.99 & 6.77 & 7.94 & 10.04 \\
\hline MnO & 0.20 & 0.19 & 0.19 & 0.19 & 0.27 & 0.15 & 0.14 & 0.13 & 0.16 & 0.13 \\
\hline MgO & 15.64 & 15.54 & 15.63 & 15.66 & 15.48 & 21.03 & 21.04 & 20.29 & 12.42 & 16.62 \\
\hline $\mathrm{CaO}$ & 22.20 & 22.64 & 22.27 & 22.22 & 22.08 & 12.61 & 12.73 & 12.71 & 10.08 & 12.19 \\
\hline $\mathrm{Na}_{2} \mathrm{O}$ & 0.20 & 0.20 & 0.20 & 0.19 & 0.21 & 0.08 & 0.08 & 0.13 & 0.96 & 0.92 \\
\hline $\mathbf{K}_{2} \mathbf{O}$ & 0.00 & 0.00 & 0.00 & 0.00 & 0.00 & 0.00 & 0.00 & 0.00 & 0.07 & 0.00 \\
\hline TOTAL & 99.79 & 99.94 & 99.77 & 100.01 & 100.10 & 98.26 & 98.03 & 98.08 & 100.18 & 97.74 \\
\hline Si & 1.926 & 1.932 & 1.925 & 1.931 & 1.927 & 2.091 & 2.093 & 2.057 & 1.899 & 1.856 \\
\hline $\mathbf{T i}$ & 0.008 & 0.009 & 0.009 & 0.010 & 0.010 & 0.005 & 0.003 & 0.008 & 0.006 & 0.031 \\
\hline Al & 0.075 & 0.069 & 0.071 & 0.069 & 0.073 & 0.048 & 0.050 & 0.088 & 0.704 & 0.304 \\
\hline $\mathrm{Fe}^{+3}$ & 0.071 & 0.061 & 0.074 & 0.061 & 0.067 & 0.000 & 0.000 & 0.000 & 0.000 & 0.000 \\
\hline $\mathrm{Cr}^{+3}$ & 0.001 & 0.001 & 0.001 & 0.001 & 0.002 & 0.000 & 0.000 & 0.001 & 0.000 & 0.005 \\
\hline $\mathrm{Fe}^{+2}$ & 0.157 & 0.155 & 0.154 & 0.167 & 0.172 & 0.195 & 0.185 & 0.209 & 0.243 & 0.315 \\
\hline Mn & 0.006 & 0.006 & 0.006 & 0.006 & 0.008 & 0.005 & 0.004 & 0.004 & 0.005 & 0.004 \\
\hline $\mathbf{M g}$ & 0.862 & 0.856 & 0.862 & 0.862 & 0.853 & 1.154 & 1.157 & 1.119 & 0.677 & 0.929 \\
\hline $\mathrm{Ca}$ & 0.880 & 0.896 & 0.883 & 0.879 & 0.874 & 0.497 & 0.503 & 0.504 & 0.395 & 0.490 \\
\hline $\mathrm{Na}$ & 0.014 & 0.014 & 0.014 & 0.014 & 0.015 & 0.006 & 0.006 & 0.009 & 0.068 & 0.067 \\
\hline $\mathbf{K}$ & 0.000 & 0.000 & 0.000 & 0.000 & 0.000 & 0.000 & 0.000 & 0.000 & 0.003 & 0.000 \\
\hline Total & 4.000 & 4.000 & 4.000 & 4.000 & 4.000 & 4.000 & 4.000 & 4.000 & 4.000 & 4.000 \\
\hline Wo & 46.34 & 46.99 & 46.49 & 46.08 & 46.04 & 26.94 & 27.27 & 27.50 & 30.04 & 28.25 \\
\hline En & 45.42 & 44.88 & 45.40 & 45.19 & 44.91 & 62.52 & 62.71 & 61.07 & 51.49 & 53.59 \\
\hline Fs & 8.24 & 8.14 & 8.11 & 8.73 & 9.04 & 10.54 & 10.02 & 11.43 & 18.47 & 18.16 \\
\hline $\mathbf{M g}^{\#}$ & 79.14 & 79.83 & 79.08 & 79.14 & 78.16 & 85.57 & 86.23 & 84.23 & 73.60 & 74.69 \\
\hline
\end{tabular}

Mersin ofiyolotini kesen plajiyogranitlerin içersinde gözlenen MME'lerden analiz edilen klinopiroksenlerdeki $\mathrm{Mg}^{\#}$ numaralarına karşılık plajiyoklaslardaki anortit (An) oranına göre çizilen diyagram (Şekil 9) incelendiğinde MME'lere ait örneklerin yay ortamı gabroyik alana düştükleri ve Mersin, Kızıldağ (Hebert ve Laurent, 1990), Tekirova (Antalya) (Bağcı, 2004) ve Pozantı (Parlak vd., 2000, 2002b) ofiyolitlerine ait örneklerle benzer ortama denk düştükleri ortaya konulmuştur. Çalışma alanından derlenen MME'lerde bulunan klinopiroksenlerin $\mathrm{TiO}_{2}^{\prime}$ ye karşılık $\mathrm{Mg}^{\#}$ numaralarının korelasyonunun incelendiği diyagram Şekil 10' da verilmiştir. İncelenen örneklerde $\mathrm{TiO}_{2}$ içeriklerinin değişik oranlarda olduğu gözlenmekte ve bir kısmının Mersin ofiyolitine ait mafik kümülatlarda gözlenen klinopiroksenlerin $\mathrm{TiO}_{2}$ içeriğine benzerlik sundukları gözlense de (Parlak vd., 1996) yüksek Ti içeriğine sahip örnekler hızı soğuma hızıyla ilişkilendirilmiştir.

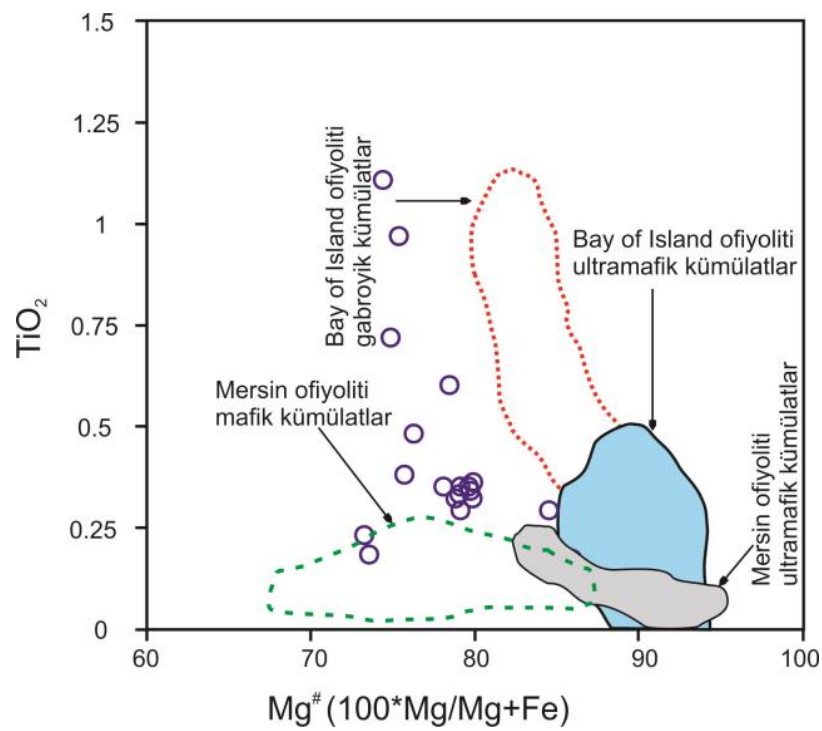

Şekil 10. Mersin ofiyolitini kesen plajiyogranitler içerisinde gözlenen MME'lere ait klinopiroksen minerallerinin $\mathrm{TiO}_{2}$ 'ye karşı $\mathrm{Mg}^{\#}$ değişim diyagramı (Coish ve Taylor, 1979; Gamble ve Taylor, 1980; Elthon, 1987; Bağcl, 2004).

Mersin ofiyolitinde gözlenen plajiyogranitler içerisindeki MME'lerden analiz edilen 
klinoprioksenlerin $\quad \mathrm{Al}_{2} \mathrm{O}_{3} \quad$ içeriklerinin $\quad \mathrm{TiO}_{2}$ içeriklerine göre korelasyonlarının değerlendirildiği diyagramda Pozantı-Karsantı ofiyolitinde gözlenen (Parlak vd., 2000) gabroyik kayalara ait klinopiroksenlere benzerlikler sundukları ve Semail ofiyolitinde gözlenen gabroyik kayalara ait (Pallister ve Hapson, 1981) düşük basınçlı klinopiroksen alanına denk düştükleri gözlenmiştir (Şekil 11).

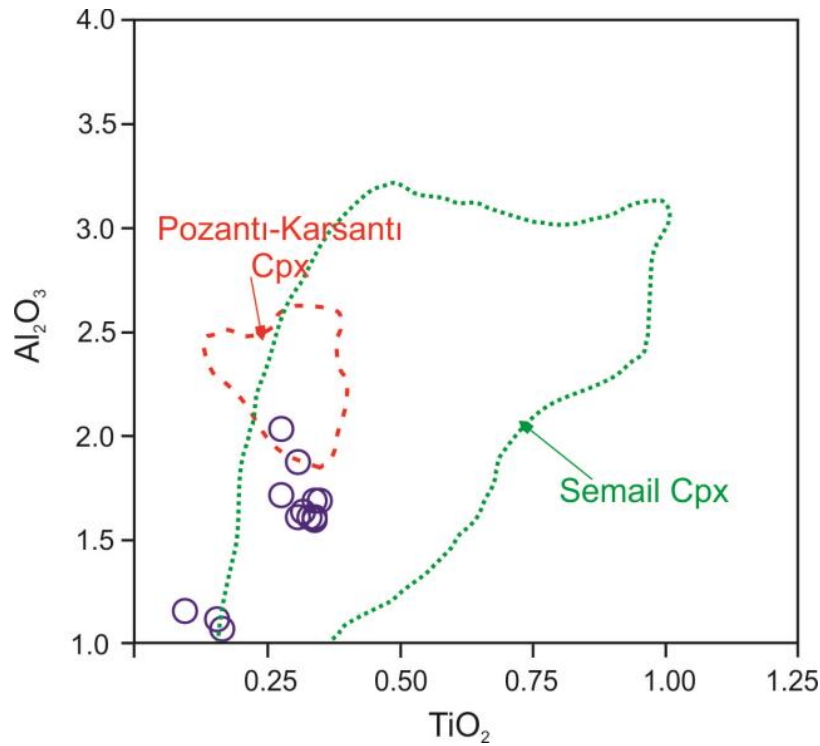

Şekil 11. Mersin ofiyolitinde gözlenen MME'lerdeki klinopiroksenlerin $\mathrm{Al}_{2} \mathrm{O}_{3}$ içeriğine karşı $\mathrm{TiO}_{2}$ içeriğinin değişim diyagramı. (PKO: Parlak vd., 2000; Semail: Pallister ve Hopson, 1981).

\section{Tartışma ve Sonuçlar}

Alp-Himalaya orojenik sistemi içinde önemli bir yere sahip olan Anadolu, yaklaşık olarak D-B uzanımlı tektonik kuşaklar arasında (Pontidler, Anatolidler, Toridler ve Kenar kıvrımlar) Paleotetis ve Neotetis okyanusal basenlerinin kalıntılarını içermektedir (Ketin, 1983; Şengör ve Yılmaz, 1981; Robertson ve Dixon, 1984). Paleotetis ile ilgili jeolojik olayların kanıtları genel olarak K-KB Türkiye'de Sakarya zonu (Karakaya Kompleksi), Konya, Karaburun ve Likya naplarında görülmektedir. (Bingöl, 1975; Tekeli, 1981; Şengör ve Yılmaz, 1981; Pickett ve Robertson, 1996, 2004; Robertson ve Ustaömer, 2009, 2012; Göncüoğlu ve Kozlu, 2000; Okay ve Göncüoğlu, 2004; Okay ve Altıner, 2004; Duru vd., 2004). Paleotetis okyanusunun kapanması Balkanlarda ve Akdeniz'in batısında Karbonifer'de meydana gelmiş (Ziegler, 1990) olup, Türkiye'yi de içine alan Doğu Akdeniz bölgesinde ise Geç Triyas'a kadar gelişimini sürdürmüştür (Robertson vd., 2009; Okay vd.,
2006). Paleotetis okyanusunun kapanması Geç Triyas'tan itibaren kuzeyde Avrasya plakasının güney kenarının (Sakarya zonu) altına dalmasıyla gerçekleşmiştir. Bununla birlikte, güneyde Ege bölgesinde ise Paleotetis okyanusunun $\mathrm{Geç}$ Karbonifer'de güneye doğru Gondwana kıtasının altına daldığına dair bulgulara da rastlanmaktadır (Zulauf vd., 2007; Robertson vd., 2012). Neotetis ile ilgili jeolojik olaylar ise Triyas'tan Miyosen'e kadar tüm Anadolu'yu etkisi altına almıştır (Şengör ve Yılmaz, 1981; Robertson ve Dixon, 1984). Güneydoğu Anadolu'da kuzeydoğu-güneybatı doğrultulu Türkiye, Kıbrıs ve Suriye'yi içine alan kuzey ve güney olmak üzere iki farklı ofiyolit kuşağının olduğu bilinmektedir (Yılmaz, 1993; Robertson 2002; Parlak vd., 2009). Kuzeyde yer alan ofiyolit kuşağı, Toros platformu ile Bitlis-Pütürge masifi arasında yer alan Göksun, İspendere, Kömürhan, Guleman ve Killan ofiyolitlerini kapsamaktadır. Güney kuşak ise, Troodos (Kıbrıs), Baer-Bassit (Suriye), Antalya (Tekirova), Hatay, Amanos ve Koçali ofiyolitlerini içermektedir. Kuzey ve Güney kuşakta yer alan ofiyolitlerin oluşumu ile ilgili farklı görüşler bulunmaktadır. Her iki kuşakta yer alan ofiyolitlerin Toros platformu ile Arap platformu arasında kalan tek bir okyanusal basenden türediği bazı yazarlar tarafından ileri sürülmektedir (Şengör ve Yılmaz, 1981; Robertson ve Dixon, 1984; Yılmaz, 1993; Yılmaz vd., 1993). Diğer bir görüşe göre ise; güneyde yer alan ofiyolit kuşağının Geç Kretase'de Güney Neotetis okyanusunda Bitlis-Pütürge masifi ve Arap platformu arasındaki okyanusal havzada kuzeye dalan okyanus içi yitim zonu üzerinde oluştuğu ve güneye doğru Arap platformu üzerine yerleştiği; kuzeyde yer alan ofiyolit kuşağının ise, Toros platformu ile Bitlis-Pütürge masifi arasında yer alan ve Berit okyanusu olarak isimlendirilen okyanusal basende kuzeye dalan okyanus içi yitim zonu üzerinde oluştuğu ileri sürülmektedir (Parlak vd., 2009; Robertson vd., 2012). Omer (2014) Mersin ofiyolitinde yapmışolduğu paleomanyetik ve yapısal çalışmalar ile tüm ofiyolit zonunun önemli ölçüde saat yönünde bir rotasyondan etkilendiğini, bunun yanında Troodos, Hatay ve Baër Bassit ofiyolitlerinde ise saat yönü tersine bir rotasyon görüldügünü belirterek bu ofiyolitlerin farklı 
kuşaklarda yer alması gerektiğini öne sürmüştür. Kuzey kuşaktaki ofiyolitler metamorfik MalatyaKeban platformu tarafından tektonik olarak üzerlenmekte ve Geç Kretase-Eosen yaşlı granitoyidler tarafından kesilmektedir (Yılmaz vd., 1993; Parlak, 2006; Rızaoğlu vd., 2009; Karaoğlan vd., 2013a). Juteau (1980), Türkiye Ofiyolitleri isimli çalışmasında, Orto Toros ofiyolitlerinin özelliklerini ayrıntılı olarak incelemiştir. Araştırmacı Toros ofiyolitlerinin tabandan tavana doğru değişik yaşlarda birden çok tektonik birliğin bir araya gelmesiyle karmaşık bir yapı gösterdiğini belirterek; bu birimlerin genel olarak aşağıdan yukarıya: volkanik ve sedimanter birim, metamorfik kayaçların oluşturduğu birim ve kaba taneli, toleyitik kayaçlardan oluşan büyük bir birim ile ilk iki birimi kesen diyabaz dayaklarından oluştuğunu belirtmiştir. Yazar Mersin ofiyolitinde yaptığı çalışmada, bu birimlerin; çok iyi foliasyon gösterdiğini, serpantinize olmuş büyük harzburjit dilimleri ve bu dilimlere paralel, santimetre düzeyindeki kalınlıklarda yer yer dünit gözlendiğini belirtmiştir. Bunların altında da metamorfik, volkanik ve sedimanter serilerin yer aldığını belirterek, tüm bu birimlerin tabanında kırmızı radyolaritler, masif kireçtaşı blokları, ezilmiş kahverengi lav seyelerinden oluşan "renkli melanj" dan söz etmiş, Mersin ofiyolitlerinin yapısal özelliğinin Toros Kuşağındaki diğer masiflere benzediği belirtilmişir (Şekil 1).

Bağcı ve Parlak, (2009) Toros ofiyolit kuşağında gözlenen Tekirova (Antalya) ofiyolitinin petrolojisi üzerine yaptıkları çalışmada, Tekirova ofiyolitinin harzburjitik tektonitler, ultramafik-mafik kümülatlar, izotopik gabrolar ve levha dayklarından oluştuğunu ortaya koymuşlardır. Parlak vd. (2000) Pozantı-Karsantı ofiyolitinin dalma-batma zonu üzerinde ve manto tektonitleri, ultramafik- mafik kümülatlar, izotropik gabrolar, levha daykları, bazaltik volkanikler ve bu birimleri kesen izole diyabaz dayılarından oluştuklarını ortaya koymuşlardır (Şekil 3c). Şimdiye kadar yapılan çalışmalarda Mersin (Pozantı-Karsantı, Ali hoca vb.) ofiyolitinin oluştukları jeodinamik ortamın dalmabatma zonu (SSZ) olduğu ve Geç Kretase döneminde oluştuğu ortaya konulmuştur (Parlak vd., 1996,
2000). Pozantı-Karsantı ofiyolitinin dalma-batma zonu üzerinde ve manto tektonitleri, ultramafik kümülatlar, mafik kümülatlar, izotropik gabrolar ve levha daykları, bazaltik volkanikler ve bu birimleri kesen izole diyabaz dayklarından oluştuklarını ortaya koymuşlardır. Şimdiye kadar yapılan çalışmalarda Mersin (Pozantı-Karsantı, Ali hoca vb.) ofiyolitinin jeodinamik ortamın dalma-batma zonu (SSZ) olduğu ve Geç Kretase döneminde oluştuğu ortaya konulmuştur (Parlak vd., 1996, 2000). Çalışma alanında gözlenen asidik kayalar Türkmen (1994)'te magmatik kaya kompleksi olarak tanımlanmıştır. Ancak bölgede yapılan detaylı arazi çalışmaları sonucunda birimlerin dayk şeklinde oldukları ve Parlak (1996)'da belirtildiği gibi plajiyogranit oldukları kabul edilmiştir. Plajiyogranitlerin okyanusal kabuktaki ve ofiyolitlerdeki oluşumları ilgi çekici bir konudur, gerek tartışmalı kökenleri ve gerekse dikkat çekici bileşimleri ile üzerlerinde özel çalışma gereken konuyu oluşturmaktadırlar (Nurlu vd. 2018b). Çalışma alanından derlenen MME'ler bileşimsel olarak Mersin ofiyolitine ait izotrop ve kümülat gabrolara benzer özellik sunmakta olmakla birlikte, Mersin ofiyolitini keser vaziyetteki plajiyogranitler içerisinden elde edilen örneklerde ileri derecede ayrışma gözlenmektedir. Çalışılan MME'lere ait plajiyokların An içeriklerinin ve $\mathrm{Mg}^{\#}$ numaralarının Mersin ofiyolitine ait gabrolara kıyasla daha düşük oranlarda olduğu gözlenmiştir (Şekil 9). Belirtildiği üzere Güney Anadolu bölgesindeki ofiyolitik kuşaklara ait çok sayıda jeokimyasal ve petrolojik çalışma gerçekleştirilmiştir. Ancak Mersin ofiyoliti içindeki plajiyogranitler bünyesindeki gabroyik anklavların petrolojik incelemesine ve buna yönelik tektonik ortam yorumuna dair bilgi eksikliği mevcuttur. Bu çalışmada Mersin bölgesindeki Mafik Mikrogranular Anklavların (MME) petrografik, mineral kimyası ve arazi ilişkileri incelenerek Mersin ofiyolitini kesen plajiyogranitler içerisinde boyutları $5 \mathrm{~cm}$ 'den $50 \mathrm{~cm}$ 'e kadar değişen MME'ler tanımlanmıştır. Bu kayaçlar üzerinde detaylı petrografik analizler yapılmış ve çoğunlukla gabroyik, az olarak ise diyoritik karakterde kayaç grupları belirlenmiştir. MME'ler üzerinde yapılan mineral kimyası analizleri sonucunda; plajiyoklasların Anortit (An) içerikleri 88.5 ile 90.8 
arasında değiştiği ve anortit- bitovnit bileşiminde oldukları ortaya konulmuştur. Analiz edilen MME'lerden elde edilen klinopiroksen analizlerinin Mg $^{\#}$ numaraları 73.60 ile 86.28 arasında değişmektedir ve Klinopiroksenlerin Wo-En-Fs üçlü diyagramında değerlendirilen veriler ışı̆̆ında diyopsit oldukları belirlenmiştir. Çalışılan MME'lerin Mersin ofiyolitine ait mafik kümülatlara benzer özellikler sundukları ve önceki çalışmalar ile uyumlu olmak üzere ada yayı ortamında oluştukları ortaya konulmuştur.

\section{Teşekkür}

Bu makale Çukurova Üniversitesi Bilimsel Araştırma Fonu tarafından desteklenmiştir (Proje No: FBA-2018-10777). Yazarlar mineral kimyası analizleri için Alberta Üniversitesinden Dr. Andrew LOCOCK'a ve bu makalenin geliştirilmesinde önemli katkılar sunan iki hakeme teşekkür ederler.

\section{Kaynaklar}

Akal, C., Helvacl, C., 1999. Mafic Microgranular Enclaves in the Kozak Granodiorite Western Anatolia. Tr. J. of Earth Sciences, 8, 1-17.

Arculus, R.J., and WILLS, K.J.A., 1980. The Petrology of Plutonic Blocks and Inclusions from the Lesser Antilles Island Arc. Journal of Petrology, 21, 743-799.

Armstrong, J.T., 1988. Quantitative analysis of silicates and oxide minerals: Comparison of Monte-Carlo, ZAF and Phi-Rho-Z procedures, Microbeam Analysis, 239246.

Bağcı, U., 2004. Kızıldağ (Hatay) ve Tekirova (Antalya) Ofiyolitlerinin Jeokimyası ve Petrolojisi. Doktora Tezi, Çukurova Üniversitesi Fen Bilimleri Enstitüsü, Adana, (Yayınlanmamış).

Bağcl, U., Parlak, O. 2009. Petrology of the Tekirova (Antalya) ophiolite (Southern Turkey): evidence for diverse magma generations and their tectonic implications during Neotethyan-subduction, International Journal of Earth Sciences 98(2):387-405.

Barbarin, B., 1991. Constrasted Origins fort he Poligenic and Monogenic Enclaves Swarms in Some Granitoids of the Sierra Nevada Batholith, Californiai Terra Abstr., 3,32.

Bingöl, E., 1975. Batı Anadolunun jeotektonik evrimi. MTA Dergisi, 86, 14-34.

Burns, L.E., 1985. The Border Ranges Ultramafic and Mafic Complex, South Central Alaska: Cumulate Fractionates of Island Arc Volcanics. Canadian Journal of Earth Sciences, 22, 1020-1038.
Coish, R.A., and Taylor, L.A., 1979. The Effects of Cooling Rate on Texture and Pyroxene Chemistry in DSDP Leg 34 Basalts: A Microprobe Study. Earth Planet. Sci. Lett, 42, 389-398.

Didier, J., Barbarin, B., 1991. Enclaves and Granite Petrology. Developments in Petrology 13. Elsevier, Amsterdam. 625.

Dilek, Y., and Moores E.M., 1990. Regional tectonics of the eastern Mediterranean ophiolites. In: Malpas, J., Moores, E., Panayiotou, A., and Xenophontos, C., (eds.) Ophiolites-oceanic crustal analogues. Proceedings of Troodos ophiolite symposium, 1987, 295-309.

Donovan, J.J., Snyder, D.A., and Rivers, M.L., 1993. An Improved Interference Correction for Trace Element Analysis in Microbeam Analysis, 2, 23-28.

Duru, M., Pehlivan Ş., Şentürk Y., Yavaş, F., ve Kar, H., 2004. New results on the lithostratigrapy of the Kazdağ Massif in nortwest Turkey, Turkish journal of Earth Sciences' A special issue commemorating, Okan Tekeli', Pp: 177-186.

Elthon, D., 1987. Petrology of the Gabbroic Rocks from the Mid-Cayman Rise Spreading Center. J. Geophys. Res, 92, 658-682.

Gamble, R.P., and Taylor, L.A., 1980. Crystal/Liquid Partioning in Augite: Effects of Cooling Rate. Earth Planet. Sci. Lett, 47, 21-33.

Göncüoğlu,M.C., Kuwahara, K., Tekin,U.K., and Turhan, N., 2004. Upper Permian (Changxingian) radiolarian cherts within the clastic successions of the "Karakaya Complex" in NW Anatolia, Turkish Journal of Earth Science, 13, 201-213.

Green, T.H., and Ringwood, A.E., 1968. Genesis of the Calk-Alkaline Igneous Rock Suite, Contributions to Mineralogy and Petrology, 18, 105- 162.

Hebert, R., and Laurent, R., 1990. Mineral Chemistry of the Plutonic Section of the Troodos Ophiolite: New Constraints for Genesis of Arc-Related Ophiolites. In: Malpas, J., Moores, E., Panayiotou, A., and Xenophontos, C. (eds.), Ophiolites, Oceanic Crustal Analogues, Proceeding Troodos Ophiolite Symposium, 1987, 149-163.

Juteau, T., 1980. Ophiolites of Turkey. Ofioliti, 2, 199-235. Karaoğlan, F., Parlak O., Klötzli U., Thöni M., \& Koller F. 2013a. U-Pb and Sm-Nd geochronology of the Kızıldağ (Hatay, Turkey) ophiolite, implications for the timing and duration of suprasubduction zone type oceanic crust formation in southern Neotethys, Geological Magazine, 150, 283-299.

Ketin, İ., 1983. Türkiye Jeolojisine Genel Bir Bakış, İstanbul Teknik Üniversitesi (iтÜ) Kütüphanesi Sayı, 1259,iтÜ Matbaası, Gümüşsuyu - İstanbul, 595. 
Lacroix, A., 1890. Sur Les Enclaves Acides Des Roches Volcaniques d' Auvergne, Bull. Serv. Carte Geol. Fr., 2, 25-56.

Leake B.E., Woolley, A.R., Arps, CES., Birch, W.D., Gilbert, M.C., Grice. J.D., Hawthorne, F.C., Kato, A., Kisch, H.J., Krivovichev, V.G., Linthout, K., Laird, J., Mandarino, J.A., Maresch, W.V., Nickel, E.H., Rock, N.M.S., Schumacher, J.C., Smith, D.C., Stephenson, N.C.N., Ungaretti, L., Whittaker, E.J.W., Guo, Y., 1997. Nomenclature of amphiboles: Report of the subcommittee on amphiboles of the International Mineralogical Association, Commission on New Minerals and Mineral Names. Can Mineral 35, 219246.

Nesbitt, R. W., and Hamilton, D. L., 1970. Crystallization of an Alkali Olivine Basalts under Controlled PO2PH2O Conditions, Phys. Earth Plan. Int, 3, 309-315.

Nurlu N., Türkmen S., Stepanov A.S., 2018 (a) LA-ICP-MS Zircon U-Pb Geochronology and Geochemistry of Late Cretaceous Granitoids in the Tauride Suture Zone (Mersin, S Turkey). 8. Geochemistry Symposium Antalya/Turkey. 61-62.

Nurlu N., Türkmen S., Şimşek G., Stepanov A.S., 2018 (b) Geochemistry and zircon $\mathrm{U}-\mathrm{Pb}$ geochronology constrains late cretaceous plagiogranite intrusions in Mersin ophiolite complex (southern Turkey). Arabian Journal of Geosciences (2018) 11:745.

Okay, A.I., Satir M., ve Siebel W., 2006. Pre-Alpide orogenic events in the Eastern Mediterranean region, European Lithosphere Dynamics, Geological Society, London, Memoirs, 32, 389-405.

Okay, A.I. and Altıner, D. 2004. Uppermost Triassic Limestone in the Karakaya Complex-stratigraphic and tectonic significance. Turkish Journal of Earth Sciences, 187-199.

Okay, A.I.,, ve Göncüoğlu M.C., 2004. The Karakaya Complex, A review of data and concepts, Turkish Journal of Earth Sciences, 13, 77-95.

Omer, A.F. 2014. Integrated geophysical, geochemical and structural Analysis of the Mersin Ophiolite, Southern Turkey. PhD Thesis, School of Geography, Earth and Environmental Sciences, University of Plymouth, 259p.

Pallister, J. S., and Hopson, C. A., 1981. Semail Ophiolite Plutonic Suite. Field Relation, Phase Variation, Cryptic Variation and Layering, and Model of a Spreading Ridge Magma Chamber. J. Geophys. Res, 86, 25932644.

Pandjasawatwong, Y., Danyushevsky, L.V., Crawford, A.J., and Harris, K.L., 1997. An Experimental Study of the Effects of Melt Composition on Plagioclase-Melt Equilibria at 5 and 10 kbar: Implications for the Origin of Magmatic High-An Plagioclase. Contrib. Mineral. Petrol, 118, 420-432. Makale içinde atıf yapılmamış

Parlak O., 2006. Geodynamic significance of granitoid magmatism in the southeast Anatolian orogen: geochemical and geochronogical evidence from Goksun-Afsin (Kahramanmaras, Turkey) region. Internatıonal Journal of Earth Sciences, vol.95, pp.609-627.

Parlak, O., and Delaloye M., 1996. Geochemistry and timing of post-metamorphic dyke emplacement in the Mersin ophiolite (Southern Turkey): new age constraints from ${ }^{40} \mathrm{Ar} /{ }^{39} \mathrm{Ar}$ geochronology. Terra Nova, 8, 585-592.

Parlak O., Delaloye M., Bingöl E., 1996. Mineral chemistry of ultramafic and mafic cumulates as an indicator of the arc-related origin of the Mersin ophiolite (southern Turkey). Geol Rundsch 85:647-661.

Parlak, O., Delaloye, M., and Bingöl, E., 1995. Origin of sub-ophiolitic metamorphic rocks beneath the Mersin ophiolite. Ofioliti, 20, 97-110.

Parlak, O., Höck, V., and Delaloye, M., 2002b. The SupraSubduction Zone Pozanti-Karsanti Ophiolite, Southern Turkey: Evidence for High-Pressure Crystal Fractionation of Ultramafic Cumulates. Lithos, 65, 205- 224.

Parlak, O., Höck, V., Delaloye, M., 2000. Suprasubduction Zone Origin of the Pozantı-Karsantı Ophiolite (Southern Turkey) Deduced from Whole Rock and Mineral Chemistry of The Gabbroic Cumulates, In: Bozkurt, E., Winchester, J. A., Piper, J. D. A (eds.), Tectonics and Magmatism in Turkey and the Surrounding Area. Geol. Soc. London, Special Publication, 173, 219-234.

Parlak, O., Rizaoğlu T., Bağci U., Karaoğlan F., ve Höck, V., 2009. Tectonic significance of the geochemistry and petrology of ophiolites in southeast Anatolia, Turkey. Tectonophysics, 473, 173-187.

Pickett, E.A., ve Robertson A.H.F., 1996. Formation of the Late Paleozoic-Early Mesozoic Karakaya complex and related ophiolites in northwestern Turkey by Palaeotethyan subduction-accretion. Journal of the Geological Society of London, 153, 995-1009.

Pickett, E.A., ve Robertson A.H.F., 2004. Significance of the volcanogenic Nilufer unit and related components of the Triassic Karakaya Complex for Tethyan Subduction/Accretion Processes in NW Turkey. Turkish Journal of Earth Sciences, 13, 97-143.

Rızaoğlu T., Parlak O., Hoeck V., Koller F., Hames W.E., Billor Z., 2009. Andean-type active margin formation in the eastern Taurides: Geochemical and geochronogical evidence from the Baskil granitoid 
(Elazig, SE Turkey). Tectonophysics, vol.473, pp.188207.

Ricou, L.E., 1971. Le croissant ophiolitique péri-arabe, une ceinture de nappes mises en place au Crétacé supérieur. Rev. Géogr. phys. Géol. dyn., Paris, 13, 327349.

Robertson, A.H.F., 1994. Role of the tectonic facies concept in orogenic analysis and its application to Tethys in the eastern Mediterranean region. Earth Science Review, 37, 139-213.

Robertson, A.H.F., 2002. Overview of the genesis and emplacement of Mesozoic ophiolites in the Eastern Mediterranean Tethyan region. Lithos, 65, 1-67.

Robertson, A.H.F., ve Ustaömer, T., 2012. Testing alternative tectono-stratigraphic interpretations of the Late Palaeozoic - Early Mesozoic Karakaya Complex in NW Turkey, support for an accretionary origin related to northward subduction of Palaeotethys. Turkish Journal of Earth Sciences, 21, 961-1027.

Robertson A.H.F., Karamata S. and Sarić K., 2009. Overview of ophiolites and related units in the Late Palaeozoic-Early Cenozoic magmatic and tectonic development of Tethys in the northern part of the Balkan region. Lithos, 108: 1-36.

Robertson, A.H.F., Parlak O., Ustaömer, T., 2012. Overview of the Palaeozoic - Neogene evolution of neotethys in the Eastern Mediterranean region (southern Turkey, Cyprus, Syria), 18, 4, 3381-404.

Robertson, A.H.F., ve Ustaömer, T., 2009. Upper Palaeozoic subduction/accretion processes in the closure of Palaeotethys, Evidence from the Chios Melange (E Greece), the Karaburun Melange (W Turkey) and the Teke Dere Unit (SW Turkey). Sedimentary Geology, 220, 29-59 .

Robertson, A.H.F.,ve Dixon, D.E., 1984. Introduction, aspects of the geological evolution of the eastern Mediterranean, ed: Dixon, J.E., and Robertson, A.H.F., The geological evolution of the eastern Mediterranean, Spec.Publ.of. Geol.Soc.of London,17, 1-7.

Sisson, T.W., and Grove, T.L., 1993. Experimental Investigation of the Role of $\mathrm{H} 2 \mathrm{O}$ in Calk-Alkaline Differantiation and Subduction Zone Magmatism. Contrib. Mineral. Petrol, 113, 143-166.

Şengör, A.M.C., and Yılmaz, Y., 1981. Tethyan evolution of Turkey: Plate tectonic approach. Tectonopysics, 75, 181-241.

Tekeli, O., 1981. Subduction complex of pre-jurassic age, north Anatolia, Turkey. Doktora tezi, Geology, (1981).

Türkmen, S., 1994. Pamukluk barajının (Tarsus) mühendislik jeolojisi incelemesi. Doktora tezi,
Çukurova Üniversitesi, Fen Bilimleri Enstitüsü, Adana, 204 s.

White, A.J.R. and Chappell, B.W., 1977. Ultrametamorphism and granitoid genesis. Tectonophysics, 43, 7-22.

Yilmaz, Y., 1993. New Evidence and Model on the Evolution of the Southeast Anatolian Orogen. Bulletin Geological Society of America, 105:251-71.

Yılmaz, Y., Yiğitbaş, E., Genç, Ş.C., 1993. Ophiolitic and metamorphic assemblages of southeast Anatolia and their significance in the geological evolution of the orogenic belt. Tectonics,12/5,1280 - 1297.

Ziegler, P.A. 1990. Geological Atlas of Western and Central Europe. 2nd. Ed. Shell International Petroleum Mij. B.V., distributed by Geological Society, London, Publishing House, Bath, 239 p.

Zulauf, G., Romano, S.S., Dörr, W., Fiala, J., 2007. Crete and the Minoan terranes, age constraints from $\mathrm{U}-\mathrm{Pb}$ dating of detrital zircons, ed: Linnemann, U., Nance, R.D., Kraft, P., Zulauf, G. (Eds.), The evolution of the Rheic Ocean, From Avalonian- Cadomian active margin to Alleghenian-Variscan Collision. Geological Society of America, Special Paper, 423, 401-411. 